\title{
What Tweets Tell us About MOOC Participation
}

http://dx.doi.org/10.3991/ijet.v9i1.3316

\author{
A. Koutropoulos ${ }^{1}$, S.C. Abajian ${ }^{2}$, I. deWaard ${ }^{3}$, R. Hogue ${ }^{4}$, N.Ö. Keskin ${ }^{5}$, and C.O. Rodriguez 6 \\ ${ }^{1}$ University of Massachusetts Boston, USA 2 California State University, Northridge, USA \\ ${ }^{3}$ Institute of Tropical Medicine, Belgium ${ }^{4}$ University of Ottowa, Canada \\ ${ }^{5}$ Anadolu University, Turkey ${ }^{6}$ Universidad Nacional de La Plata, Argentina
}

\begin{abstract}
In this research paper, the authors analyze the collected Twitter data output during MobiMOOC 2011. This six-week data stream includes all tweets that contain the MOOC's hashtag (\#mobiMOOC) and it has been analyzed using qualitative methodology. The analysis sought to examine the emotive vocabulary used, to determine if there was content-sharing via tweets, and to analyze the folksonomic trends of the tweets. In Addition sought a deeper understanding of what, and how, MOOC participants share what they share on the MOOC's Twitter channel. The aim of this study is to provide a little more insight into MOOC learner behaviors on Twitter so that future MOOC designers and facilitators can better engage with their learners.
\end{abstract}

Index Terms-Twitter, MOOC, cMOOC, participation, engagement

\section{INTRODUCTION}

The year 2012 saw the entrance of the Massively Open Online Course (MOOC) into the popular rhetoric surrounding higher education reform. MOOCs became popular subjects in both academic news (for examples see [16]) and the mainstream media such as the New York Times [7]. However, the type of MOOC offered by organizations such as Udacity and Coursera did not share the connectivist theoretical underpinnings of the original MOOCs. Rather, they use more behaviorist and cognistivist approaches to content delivery. In order to differentiate between the MOOCs popularized by academic institutions and the traditional MOOCs, new terminology was introduced. Specifically, the term $x M O O C$ refers to an institutional MOOC and the term $c M O O C$ refers to a connectivst MOOC $[8,9]$.

A cMOOC, as described by the person who coined the term "MOOC" [10], is an online course that offers learners a way to connect, collaborate, and engage in the learning process. It is also an event in which people can get together to talk about a topic of common interest in a structured way. The work done in the course is shared in an open way, and learning is participatory. Finally, the course is distributed, all of the available content through blogs, websites, status posts on social networks, and more, is knit together to create a course.

In 2011, Kop, Fournier, and Mak [11] began publishing studies that investigate participation in cMOOCs. At the same time, a group of participants in the cMOOC titled "MobiMOOC," a six-week cMOOC relating to mobile learning that occurred in the spring of 2011, began analyzing their experience in the MobiMOOC [12-14]. This paper continues the exploration of the MobiMOOC participant experience by examining the Twitter stream of the MobiMOOC, to answer to research question: "What can tweets tells us about MOOC participants?"

\section{RESEARCH QUESTION}

At the conclusion of MobiMOOC there was an interest to determine what, if anything, the tweeting behaviors of MOOC participants can tells us about MOOC participation. Are there are certain trends in the participants' Twitter behaviors? If so, they may be meaningfully connected to MOOC engagement and future developers and facilitators of MOOCs may be able to use these findings to increase engagement in their MOOCs. This could be done by better understanding what their own participants are doing on Twitter when they tweet about the MOOC. Throughout this paper the term MOOC is used interchangeably with the term cMOOC as the tweets analyzed where part of a cMOOC.

\section{LITERATURE REVIEW}

Since, to our knowledge, this type of Twitter analysis for MOOCs does not have published research, we examined two streams of research: (1) general research into MOOCs that has been published up to this point, and (2) research into Twitter usage behavior, both general as well as Twitter user behaviors in courses and in conferences. cMOOCs, at times, have been referred to as "Massive Online Open Conferences" by some of their participants due to their open nature. For this reason, and since MOOCs are essentially courses, we believed that research into Twitter usage in-class and Twitter usage inconferences would be good related research to seek out and examine as part of our literature review.

To date, there is only a handful of published research articles relating to MOOCs. In our search we only found 11 research articles on MOOCs, and they were all looking into the cMOOC variety, with the exception of one [15] that compared cMOOCs and xMOOCs. While MOOCs have been in existence, with their own term, "MOOC," to describe them, since 2008; due to the fact that the MOOC only became popular in wider circles in 2012, the research around this pedagogical, and technological, format for education is still relatively little. This will, undoubtedly change, as the spotlight is placed on the format, the designers who design them, and the instructors that run them. At this time, however we have a handful of articles pertinent to our discussion.

Of the published research in MOOCs, there is research that examines the nexus of MOOCs and mLearning, and the overall broad learner types and interaction types [12], as well as emergence and the nature of participation in MOOCs [13]. Further along this path of participation Koutropoulos et al [14] examined, specifically, the idea of whether or not emotive vocabulary in discussions forums 
of MOOCs may play a role in the continued participation of learners in a MOOC.

These studies dealt specifically with mobiMOOC, the same MOOC where our tweet analysis for this paper comes from. Other papers have examined demographics of MOOC participants and participation patterns in other cMOOCs [11], comparison of MOOCs [16], aspects of self directed learning in MOOCs [17], learner controlled systems and learner participation [18], as well as new ways to look at the dialogue process within these connectivist learning environments [19].

While MOOC research may still be in its infancy, general Twitter research, on the other hand, is much more plentiful. Twitter, is a microblogging service that allows users to post short messages of up to 140 characters in length ("microblogs") to their service from a web client, mobile client, or text message [20]. Twitter launched in 2006 [21] and to date has over 500 Million subscribed users [22]. This popularity makes Twitter a great contender for a service that connects MOOC participants due to its ubiquity. While there are other microblogging services, such as identi.ca, plurk, and at the time of mobiMOOC, jaiku, Twitter seemed to make a lot of sense for participants to use as a microblogging service given its popularity, existing uses in mLearning, and the access it provided to its APIs (Application Programming Interfaces).

Of the published research on Twitter we see that there is a veritable breadth in the areas of life that Twitter fits into, and has already been researched. We see Twitter research examining the general Twitter timeline looking for characteristics of users, types of tweets, examinations of Twitter content types, differences between languages on Twitter, and follower-followee relationships [23-35]. In this general Twitter research area, we also see that there has been a keen interest on the self-categorization of messages by means of hashtagging [36-38] as well as the propagation on Twitter messages, specifically retweeting, which is repeating, in whole or in part, another person's tweet [39-42]. Finally, we also see that researchers are interested in looking at specific segments of Twitter users, including those who tweet personally or organizationally for various industries, both for profit and non-profit, and those who tweet in the government [43-45].

More pertinent to the background of this paper is Twitter usage research when the subject matter is Twitter in classroom, Twitter usage during conferences, Twitter usage by academics; and to some extension Twitter usage as part of the development of Personal Learning Environments (PLE). The cMOOC doesn't neatly fit into one category, which necessitates looking at Twitter usage behaviors in a variety of learning models. While the " $\mathrm{C}$ " in MOOC stands for "course," the open nature of the cMOOC allows learners, generally speaking, to come and go as they please in each weekly session; and it allows participants to participate in a variety of media and groups, not necessarily being confined on one service or virtual space. In this instance the class can feel a bit like a conference, with participants coming and going from various sessions and media.

In general terms, we see some research that looks at academic's own practices on Twitter [46], this is similar to other research on Twitter usage patterns but with academics as the user group. We see examples of Twitter use in the classroom where the aims were to deepen engagement in the course (especially in larger courses), and determine if this helps with student assessments, but also to examine the interaction and content submission patterns of students had throughout the Twitter use in the class [47-54]. Finally, we examples of Twitter research being undertaken with conference tweet data [55-59]. In this research we see the dynamics of Twitter participation in conferences, differences between physical and online attendance at conferences, and the utility of tweets produced during a conference for individuals outside of that conference.

\section{Methodology}

In this study, the authors use qualitative research techniques to analyze data collected from the MobiMOOC Twitter stream. The nature of our research was exploratory as we were analyzing transcripts that we had available after the MOOC ended. We didn't originally plan to collect Twitter data for this purpose, but since we had this public data we wanted to analyze it. The data was analyzed qualitatively for underlying themes that help to elucidate the ways in which participants in MobiMOOC interact. Also, the data was analyzed for emotive content as well as content type (plain tweet, or hyperlink to another location). We also conducted a folksonomic category analysis through the use of hashtags.

\section{A. Data Collection}

The collection of data for this analysis was incidental in nature. One of the co-authors, Sean C. Abajian, who was also a participant in MobiMOOC, setup a Crowdmap collector for all tweets with the MobiMOOC Hashtag. Crowdmap (http://www.crowdmap.com), is based on the Ushahidi platform which collects data and allows for data visualization and interactive mapping [60]. This tool was quite useful, and we have also referenced in a previous paper [12]. The tool collected tweets that contained the \#mobiMOOC hashtag for the six-week duration of the MOOC, between March 2011 and May 2011. The original purpose of this collector was to show participants where their fellow participants came from, and to also experiment with the software. However, this data seemed useful for studies of MobiMOOC afterwards.

\section{FINDINGS \& DiscuSSION}

\section{A. Descriptive Analysis of Tweets}

Our first pass through the Twitter data was a descriptive analysis of the twitter statistics in MobiMOOC. With this quantitative analysis there were a number of elements that we set out to investigate. First, we wanted to do a comparison between the Twitter data, that we had available for this inquiry, with our published results for discussion forum activity during the same MOOC [14]. Second, we wanted to compare the activity in different types of tweets, such as original tweets, retweets and replies to tweets. Third, since a common use of Twitter is to share links [23, $25,31,32,39,45,55]$, we wanted to see how many of the mobiMOOC participants shared links with their fellow participants. Finally, as compared to our previous work on emotive vocabulary usage [14] we wanted to, again, compare emotive data from Twitter activity with discussion board activity.

In comparing the activity that was happening on Twitter (this study) to that that was happening in the discussion forums [14] we were expecting to see a higher volume of 
tweets as compared to discussion board postings. On the one hand we expected the discussion boards to have a broader appeal for mobiMOOC participants and therefore expected discussion boards to be used by more participants. The two reasons for this were: First, discussion boards were the main means of communication for the course as advertised by the MobiMOOC wiki (the analog for a course home page); and second discussion boards have been around for much longer than microblogging (Twitter). Therefore if we examine it through the Technology Acceptance Model lens [61] discussion boards would be seen as easier to use, more useful, and therefore this would lead to a more positive attitude and a greater intention to use.

On the other hand, despite the expected smaller population of Twitter users, we hypothesized that the space limitation of an average tweet would mean that the average user would have a higher post-count, as compared to discussion forums. Also, since tweets do also serve as backchannel communication for live events [53, 55, 57-59] and are used for synchronous chat-type of activity, such as those found in \#phdchat and \#lrnchat, we expected a higher number of tweets as compared to discussion forum posts.

Our results however surprised us. Only during Week 1 of mobiMOOC was the Twitter post-count higher than the discussion board count. This trend did not last, and for the remaining five weeks of the MOOC Twitter posts were fewer than on the discussion board (Fig. 1). The interesting thing to note is that despite the lower post-count for the majority of the MOOC, the trends in Twitter post counts mirrored the trends in the discussion board. Taken together, these two data points may indicate the level of interest in the weekly topic and engagement in the course.

The second aspect of the Twitter data we wanted to investigate was the frequency of the different types of tweets, and to compare those to the overall trends discovered earlier. In our investigation we have three types of tweets: Original tweets defined as tweets initiated by a user without directly responding to another Twitter user; re-tweets which are defined as tweets originated by another user (another user's original tweets) but rebroadcast by some other user due to some interest in the original content, and giving credit to the original poster [62] and finally replies which are public tweets that start with @username and contain a message directed to the username, or is about the username [62].

Looking at our data (Fig. 2 and Fig. 4) we notice a few interesting things. First, original tweets and replies have a similar pattern to the overall Twitter and discussion board participation patterns; meaning there is a high amount of posts during the first two weeks, there is a noticeable drop during weeks three and four, and there is a recovery during the last two weeks. The trends of original tweets and replies seems to lend some credence to the idea that during MOOCs there is an initial excitement period where participants do post a lot and interact with their fellow participants. However, as the MOOC progresses that interest, or novelty, wears off and there is a smaller volume of peer-to-peer participation as participants leave the MOOC or lurk. During this initial excitement period there is also a lot of word-of-mouth marketing occurring to advertise the MOOC, which can explain, to some extent, the initial high counts of tweets, and retweets, during week one.
Retweets are also quite interesting to look at. Unlike original tweets and replies, retweets show a steady decline throughout the MOOC. The initial tweet count for retweets is quite high, most likely due to word of mouth advertising of the MOOC, but it steadily declines over a period of time. This is not surprising given that the source material for retweets (original tweets and replies) area also declining. It is quite interesting, however, to note that the number of retweets exceeds the number of original tweets during the low point of participation in the MOOC (weeks three and four). This may be an indicator of more passive participants in the MOOC. Individuals who have may have been lurking, or participating minimally, coming up and resurfacing during the MOOC's low-tide period.

Next we looked at the sharing of resources via Twitter by MobiMOOC participants. This was of interest for a variety of reasons. First, some of the existing research on Twitter user behaviors has indicated that sharing is one of the major activities in Twitter [23, 26, 35, 39, 43, 46, 56]. We wanted to see if our Twitter data is also mostly about information sharing (with the form of a hyperlink), mostly conversational (chats and replies) or reflective (original tweets) in nature. Second, some research on mobile microblogging has shown that mobile microbloggers don't share as many links in their tweets as compared to desktop microbloggers [63]. Thus, a high number of messages with links would seem to imply that mobiMOOC Twitter users participate on Twitter, for mobiMOOC purposes, via their desktop. Finally, we wanted to see what the trends were for sharing of links in mobiMOOC.

The Twitter link-sharing data was quite interesting. First we see that sharing links on Twitter was indeed the major activity on Twitter as far as mobiMOOC tweeting goes. This also implies that, based on previous research, the majority of Twitter activity for mobiMOOC took place on non-mobile environments. We feel confident in making

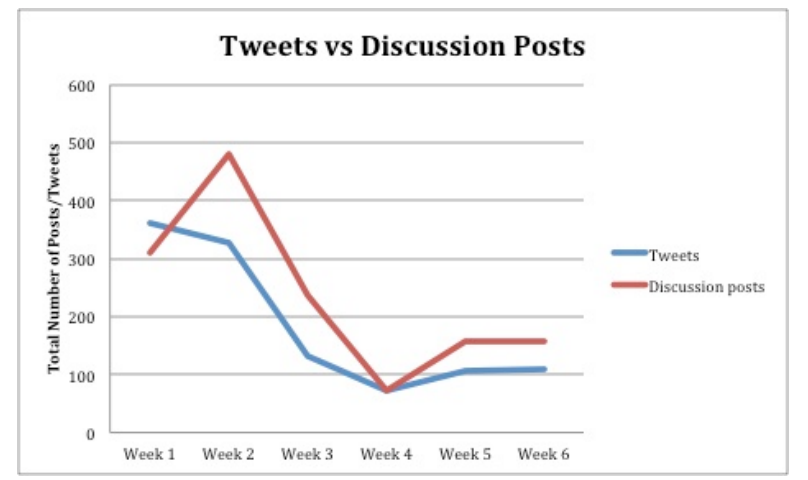

Figure 1. Comparison of Twitter usage versus discussion board usage

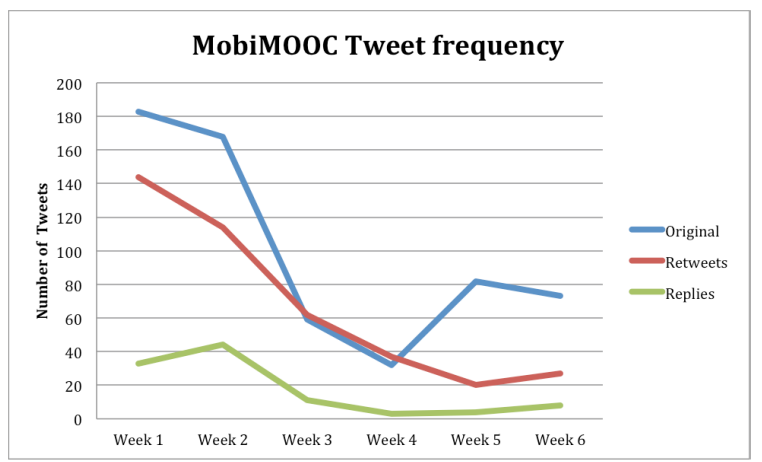

Figure 2. Types of tweets throughout the duration of MobiMOOC 


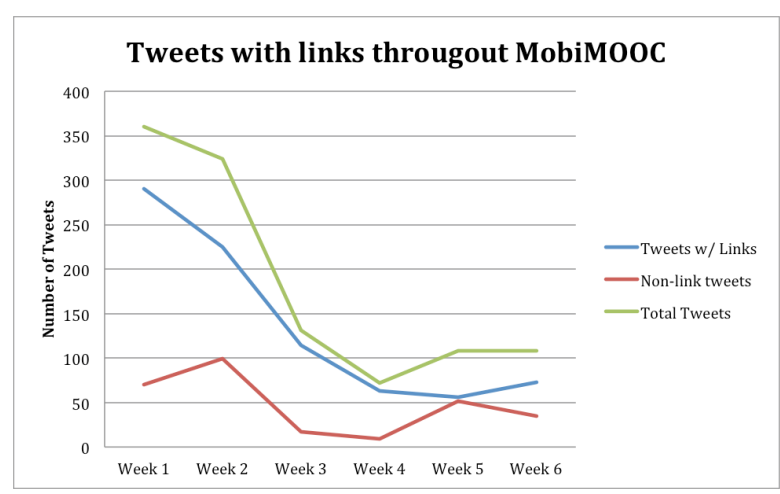

Figure 3. Frequency of tweets with links throughout MobiMOOC

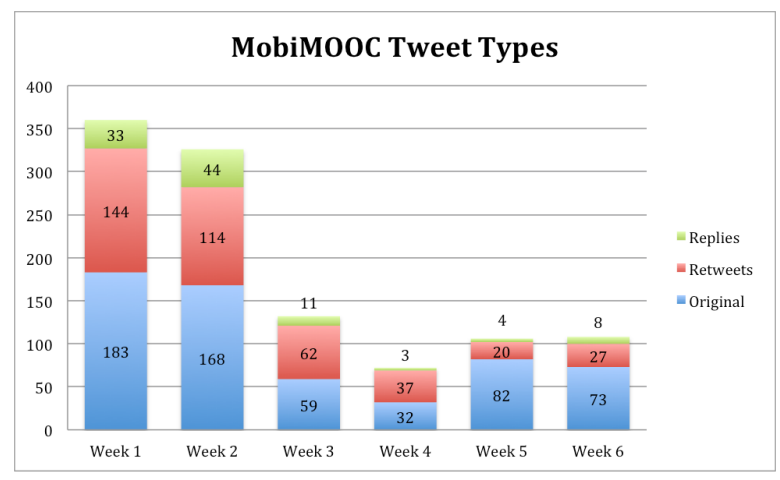

Figure 4. Breakdown of MobiMOOC tweet types

this claim because mobile operating systems and applications didn't have easy ways to sharing links to Twitter at the time mobiMOOC took place. Thus, participants browsing the web on their mobile device would not have had an easy time sharing links as compared to their peers who were participating via a desktop interface.

In late 2011, after the end of MobiMOOC, Apple released iOS version 5 which "baked in" Twitter integration. This meant that sharing links on Twitter was as simple as bookmarking. The research that indicated that more links were shared via desktop interfaces [63] would have to be verified again for future Twitter analyses of MOOC participation. Finally, in terms of trends (Fig. 3), we see that link sharing begins with a high volume in the first week of the MOOC and steadily declines throughout the remainder of the MOOC, rebounding slightly during week six. The link sharing trajectory is fairly similar to the trajectory of the overall tweets for mobiMOOC, and the declining amount of shared links may be an indication of the continued participation of "core" group of participants, versus the higher number of non-core, yet excited, individuals advertising the MOOC in its first week.

Non-link tweets, interestingly enough, compare similarly not to the Twitter post trends of mobiMOOC, but rather the trend of discussion forum posts! By comparing Fig. 1 (discussions vs. overall tweets) and Fig. 3 (tweets with links) we see that non-link tweets start off in a lower range, they peak during week two, decline weeks three and four, rebound during week five, and decline a bit during week six. This is similar to what was found in the discussion forum participation for the same MOOC [14].

We also did a comparison of LIWC data, looking at positive and negative emotions in the tweets, and we compared the three types of tweets (Fig. 5 and Fig. 6) to the data we had from our previous research on discussion

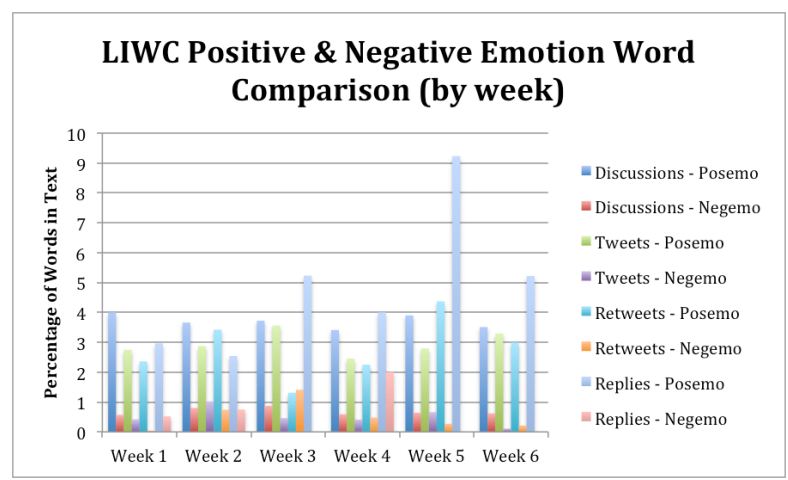

Figure 5. LIWC analysis of twitter content as compared to discussion board content throughout the duration of MobiMOOC (by Week)

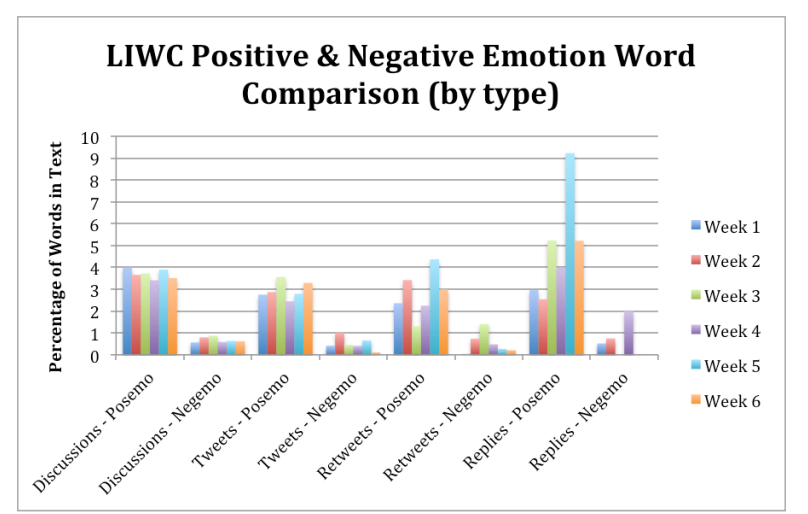

Figure 6. LIWC analysis of twitter content as compared to discussion board content throughout the duration of MobiMOOC (by Type)

board emotive vocabulary use [14]. The Linguistic Inquiry and Word Count analysis (LIWC) software determines the degree of language use in 70 other language dimensions; however as with our previous work on the discussion board analysis [14], we focused only on the expressed positive and negative emotions for this analysis [64]. The first thing we observed was that, like the discussion boards, emotive vocabulary in tweets, in the grand scheme of things, didn't really predict participation in the MOOC. It also appears that the percentage range of emotive words in tweets is half that of the discussion boards. Perhaps this is to be expected given the character limit imposed on tweets that isn't imposed on the average discussion board thread.

Despite this, there are some interesting observations. First, it seems that discussion, and original tweets, seem to hover around the same range for indications of positive emotion throughout the MOOC with little variation. Positive emotion in reply tweets, however, seems to increase throughout the MOOC reaching a peak during Week 5. This might seem to indicate a positive rapport between participants. Another interesting observation is around the relationship of positive replies to negative replies and positive retweets to negative retweets. It appears that when the reply trends to more positive vocabulary, there is a dip in the negative emotive vocabulary perhaps implying an inverse relationship. The same can be observed with the positive retweets and negative retweets. Based on the quantity of data we had and the degree of change, however, we do not believe that this proves anything definitively.

Finally, we also had a quick look to see how many of the tweets each week were posted by the weekly facilitator 
or the overall course facilitator. What we saw that that we really didn't have much participation, on Twitter, from the course facilitators. Throughout the six-week MOOC the percentage of tweets that originated from a course facilitator were $3 \%, 4.9 \%, 8.2 \% 1.4 \%, 8.5 \%$ and $5.5 \%$ for weeks one through six respectively. Even though the percentage of tweets that originated from course facilitators increases in some weeks, the number of tweets by facilitators remains relatively constant each week. Some of the regularity in tweets each week is explained by the fact that some were automatically posted by services like paper.li.

\section{B. Hashtag Trends}

Another area of research into Twitter has been the nature of hashtagging [26, 27, 31, 36, 37, 38]. Hashtagging is the practice of adding a keyword, or set of keywords, to a Twitter post. This is an ad-hoc solution to categorize the message. This is called a hashtag because the keyword is preceded by a "\#" (hash). There were three areas that we wanted to look at with regard to hashtagging during mobiMOOC. First, we wanted to have a look at the relationship between the topic of the week and the use of specific hashtags. Second, we wanted to see if there were any sustained topics throughout the MOOC that any given hashtag would indicate. Finally, we wanted to see how many hashtags per post participants used in their tweets. Here it should be noted that the mobiMOOC hashtag (\#mobiMOOC) was present in all tweets. This is, after all, how we harvested tweets from the course. The mobiMOOC hashtag is considered by our team as the null hashtag, so it wasn't included in the analysis.

In terms of original tweets, during Week 1 the topic of the course was Introduction to mLearning. During this Week $24 \%$ of the hashtags were \#mLearning and $3 \%$ were on eLearning, perhaps included by participants on Twitter as a related topic to \#mlearning. During Week 2 the topic was Planning mLearning, however our team didn't find many posts tagged for this topic. There were only two hashtags on mobile design. In Week 3 the topic was Mobile for Development (M4D), and again here we had no \#m4d or \#ict4d tagged posts. We do, however see some posts during Week 5 having \#m4d as the hashtag, perhaps indicating a connection of new information to a previous week's topic.

In Week 4 the topic of the course was Innovations in mLearning and we see that one third of the posts are actually cross-posts between mobiMOOC, and other workshops that were taking place concurrently such as Educause's edusprint. This is showing us that mobiMOOC participants took part in both events and used Twitter to post information from one event to the other, or post new information to both concurrently. Week 5 followed in the footsteps of weeks 2 and 3 in that the topic (mLearning and Societal Interactions) were not represented in the tweets of the MOOC, at least as far as self-initiated tagging went. Finally, during Week 6 , where the topic was $K$ 12 mLearning, the K-12 hashtag was in about $14 \%$ of the tweets.

When tweeting, it would seem that participants in the course don't necessarily post comments, information, and resources around the topic of the week, or at least, they don't self-report to post on the topics of the week with their hastags. So then, what do they post about? If we look at the sustained hastags, hashtags that appear in a minimum of three weeks throughout the course (Tables II and
IV) we see that participants in the course post around three general categories: Healthcare, mobile apps and hardware, and making connections to other events and institutions. One common undercurrent in MobiMOOC that wasn't an official topic of the course was mLearning in healthcare. This would seem to indicate that there were enough interested participants to sustain a topic on mLearning for healthcare, and it could potentially be included in a future mLearning course. This was the case both with original tweets and retweets

The second broad category encompasses tags in the categories of Educational Technology, Software, and Mobile Devices. This would seem to indicate that when participants thought of mLearning they thought about the technological dimension of mLearning. This, of course, in some instances mirrored discussions in the discussion boards where people shared their tips and tools when it

TABLE I.

ORIGINAL TWEET HASHTAGS (ALL)

\begin{tabular}{|c|c|c|c|c|c|c|}
\hline & \multicolumn{7}{|c|}{ Week } \\
\cline { 2 - 7 } & $\mathbf{1}$ & $\mathbf{2}$ & $\mathbf{3}$ & $\mathbf{4}$ & $\mathbf{5}$ & $\mathbf{6}$ \\
\hline Other MOOC & 3 & 3 & 8 & 0 & 0 & 0 \\
\hline Healthcare & 9 & 14 & 10 & 5 & 11 & 10 \\
\hline K-12 & 0 & 0 & 0 & 0 & 0 & 8 \\
\hline \#mooc & 0 & 0 & 4 & 0 & 0 & 0 \\
\hline eLearning & 3 & 0 & 0 & 0 & 0 & 0 \\
\hline mLearning & 27 & 16 & 12 & 8 & 4 & 12 \\
\hline Physical Mobile Device & 6 & 1 & 1 & 0 & 1 & 7 \\
\hline Software or app & 13 & 3 & 2 & 3 & 2 & 2 \\
\hline Edtech & 1 & 2 & 3 & 3 & 0 & 3 \\
\hline Conference or workshop & 16 & 9 & 4 & 14 & 1 & 2 \\
\hline Chat & 4 & 0 & 0 & 2 & 1 & 0 \\
\hline Academic Organization & 9 & 1 & 2 & 3 & 3 & 3 \\
\hline MISC & 21 & 20 & 10 & 4 & 5 & 10 \\
\hline \#m4d & 0 & 0 & 0 & 0 & 2 & 0 \\
\hline
\end{tabular}

TABLE II.

ORIGINAL TWEET HASHTAGS (SUSTAINED THROUGHOUT MOBIMOOC)

\begin{tabular}{|c|c|c|c|c|c|c|}
\hline & \multicolumn{7}{|c|}{ Week } \\
\hline & $\mathbf{1}$ & $\mathbf{2}$ & $\mathbf{3}$ & $\mathbf{4}$ & $\mathbf{5}$ & $\mathbf{6}$ \\
\hline Other MOOC & 3 & 3 & 8 & 0 & 0 & 0 \\
\hline Healthcare & 9 & 14 & 10 & 5 & 11 & 10 \\
\hline Physical Mobile Device & 6 & 1 & 1 & 0 & 1 & 7 \\
\hline Software or app & 13 & 3 & 2 & 3 & 2 & 2 \\
\hline Edtech & 1 & 2 & 3 & 3 & 0 & 3 \\
\hline Conference or workshop & 16 & 9 & 4 & 14 & 1 & 2 \\
\hline Academic Organization & 9 & 1 & 2 & 3 & 3 & 3 \\
\hline MISC & 21 & 20 & 10 & 4 & 5 & 10 \\
\hline
\end{tabular}

TABLE III.

RETWEET HASHTAGS (ALL)

\begin{tabular}{|c|c|c|c|c|c|c|}
\hline & \multicolumn{7}{|c|}{ Week } \\
\cline { 2 - 7 } & $\mathbf{1}$ & $\mathbf{2}$ & $\mathbf{3}$ & $\mathbf{4}$ & $\mathbf{5}$ & $\mathbf{6}$ \\
\hline Other MOOCs & 1 & 0 & 11 & 0 & 2 & 0 \\
\hline Healthcare & 7 & 8 & 11 & 5 & 5 & 2 \\
\hline K-12 & 0 & 0 & 0 & 0 & 0 & 2 \\
\hline eLearning & 1 & 0 & 3 & 0 & 0 & 0 \\
\hline mLearning & 38 & 20 & 16 & 17 & 2 & 5 \\
\hline Physical Device & 3 & 1 & 0 & 0 & 0 & 1 \\
\hline Software or app & 1 & 3 & 1 & 4 & 0 & 2 \\
\hline Edtech & 0 & 3 & 7 & 4 & 0 & 3 \\
\hline Conference or workshop & 31 & 36 & 22 & 22 & 0 & 3 \\
\hline Chat & 9 & 1 & 1 & 0 & 0 & 0 \\
\hline Academic Organization & 9 & 1 & 5 & 4 & 0 & 0 \\
\hline MISC & 12 & 11 & 9 & 9 & 2 & 8 \\
\hline \#ict4d \#m4d & 0 & 1 & 0 & 6 & 10 & 0 \\
\hline
\end{tabular}


TABLE IV.

RETWEET HASHTAGS (SUSTAINED THROUGHOUT MOBIMOOC)

\begin{tabular}{|c|c|c|c|c|c|c|}
\hline & \multicolumn{7}{|c|}{ Week } \\
\cline { 2 - 7 } & $\mathbf{1}$ & $\mathbf{2}$ & $\mathbf{3}$ & $\mathbf{4}$ & $\mathbf{5}$ & $\mathbf{6}$ \\
\hline Other MOOCs & 1 & 0 & 11 & 0 & 2 & 0 \\
\hline Healthcare & 7 & 8 & 11 & 5 & 5 & 2 \\
\hline mLearning & 38 & 20 & 16 & 17 & 2 & 5 \\
\hline Edtech & 0 & 3 & 7 & 4 & 0 & 3 \\
\hline Conference or workshop & 31 & 36 & 22 & 22 & 0 & 3 \\
\hline Chat & 9 & 1 & 1 & 0 & 0 & 0 \\
\hline Academic Organization & 9 & 1 & 5 & 4 & 0 & 0 \\
\hline MISC & 12 & 11 & 9 & 9 & 2 & 8 \\
\hline \#ict4d \#m4d & 0 & 1 & 0 & 6 & 10 & 0 \\
\hline
\end{tabular}

came to mLearning, and discussed software and hardware elements of mLearning. Finally, as we saw when we compared hashtags to weekly topics, another sustained trend is cross-posting information between mobiMOOC and other MOOCs ("other MOOC" category in Tables I and III), mobiMOOC and organizations of higher education ("academic organizations" category in Tables I and III), and mobiMOOC, and other conferences, and workshops that were occurring concurrently as mobiMOOC. This hashtagging trend seems to indicate that participants place the course as one of their many sources of information around the topic of mLearning and share their information to participants in all events, not just one.

Finally, we wanted to see how many hashtags participants included in their tweets. The main idea behind this was two-fold. First, we wanted to see if participants actually did tag their mobiMOOC posts or not, and if they did, we wanted to see how many tags they included per tweet. In fact, we find that in original tweets (Fig. 7) and in replies (Fig. 9) that participants do not, for the most part, tag their tweets with hashtags. They use the \#mobiMOOC hashtag (the " 0 tag") to have their tweet included in the mobiMOOC community, however for the vast majority of their activity they do not include other tags to organize their tweets. This might be the cause of such low correlation between weekly topic and tweet hashtags! When we look at retweets, the story is a tad bit different. We do see that there are a lot of retweets with just the mobiMOOC hashtag ("0 tags" in the chart), however we also do see a large amount of retweets with one tag in addition to the mobiMOOC tag.

This would seem to indicate that, as other research has pointed to [32], mobiMOOC Twitter participants modified, to some extent, the tweets that they retweeted to include additional organizing information so that they could share tweets with others who were not in mobiMOOC. An example of this would be sharing a mobiMOOC tweet with participants of other MOOCs or workshops, such as edusprint. Even so, this activity mostly takes place in the middle of the MOOC (weeks 2, 3 and 4). It seems that this type of sharing mostly happens when the course is in full swing, not as it is ramping up, or winding down.

\section{Textual Analysis of Tweets}

We also looked at the MobiMOOC Twitter corpus data from a textual analysis lens and found some interesting tweeting behaviors on the part of MobiMOOC participants. Our first step in analyzing these tweets through this lens was a quick read through all of the data, throughout all of the weeks, in order to determine what the broad categories of the content were in our Twitter corpus. Doing

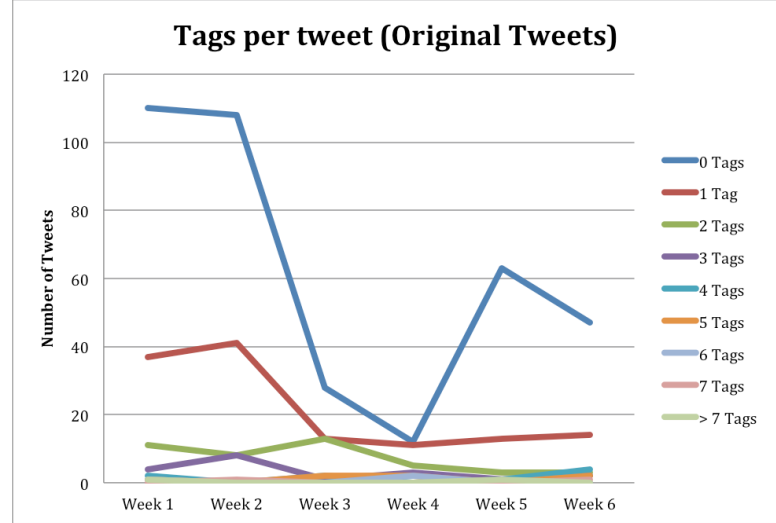

Figure 7. Hashtags per tweet for Original Tweets

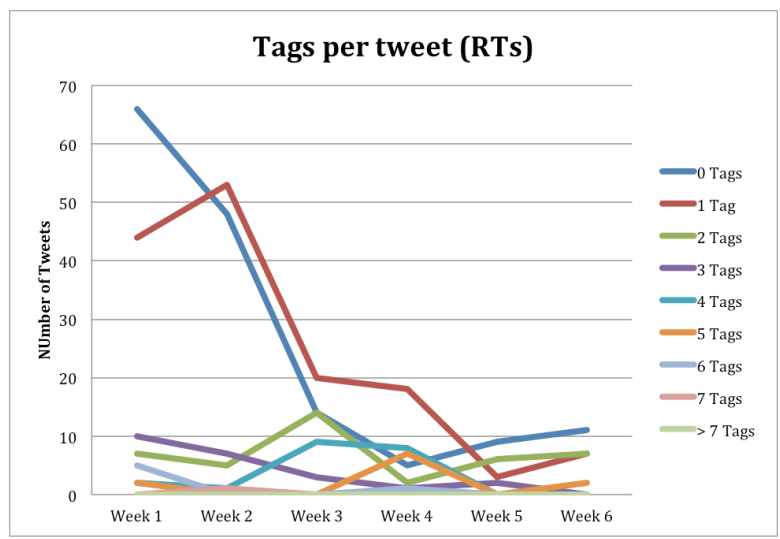

Figure 8. Hashtags per tweet for Retweets

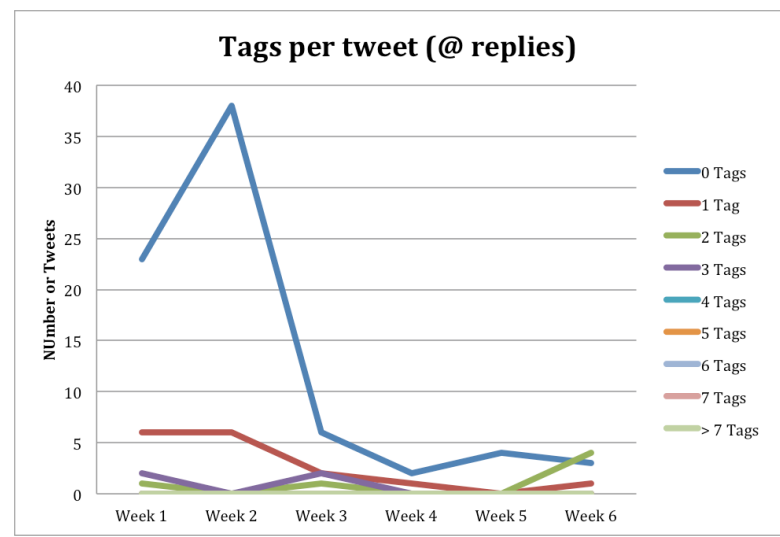

Figure 9. Hashtags per tweet for @replies

this we found that there were ten (10) broad categories into which tweets fell into.

Our major category was that of Resource or News item, where participants would, more often than not, post a link to a resource that was potentially of use to fellow participants, or a news item that related to mobile learning in some way. Another big category seemed to be commentary on participation. In this type of tweet a participant either commented on their own participation, or the participation of their peers in the MOOC. Reflection on learning was another category that was quite big throughout the MOOC, and this category was either a short tweet with some nugget of knowledge, or an "aha" moment; or a URL to a longer blog post that discussed the learning that had transpired for that particular learner. 
There were some categories that were medium in size, and those included excitement, in which participants demonstrated a positive attitude toward the MOOC, the learning process or their peers. Calls for Help was also a category that was noticeable in certain pockets of the MOOC, during certain weeks; and finally casual conversations between participants were also noticeable in certain pockets throughout the MOOC, but not as a general undercurrent of the Twitter corpus. A smaller subcategory of the casual conversation is also the thank you category in which participants thanked their peers for things such as contributed resources, retweets, or being helpful in some way.

Finally, there were some smaller categories, which included Publicizing of the MOOC by MOOC organizers, usually through a daily "newspaper" using a service such as Paper.li; or, as we saw in the first week, through the organizer's own Twitter account. We also had a very small category that included humorous or entertainment tweets, and a category that included posts that were unrelated to MobiMOOC. In the following section we will briefly describe the trends for these categories throughout the six-week MOOC, as well as demonstrate some of these categories with anonymized tweets from our corpus.

1) Week 1

During the first week of MobiMOOC the three major categories of tweets represented were: (1) the sharing of resources, information and news pertaining to mobile learning; (2) commentary on the learner's participation in the MOOC, which included excitement over participation and encouragement to get others to participate; (3) and some reflections on the learning that occurred that week in the MOOC. The smaller categories this week were publicizing of the MOOC by the organizers, which was a bit surprising; calls for help; and tweets that were off-topic in some way, such as posting videos and music, but not really making a connection to mobile learning. This may have been an attempt to create a learning community by some participants. During the first week we expected more tweets from organizers publicizing the MOOC, and we did not see this.

During this week we also see that there were tweets that pulled double duty. For example tweets that reflected both commentary on participation and reflection on learning. The calls for help aren't necessarily serious issues. Rather, they were ways for peers to get to get help and tips from one another on successful MOOC participation, as well as to receive assistance on mLearning issues dealing with software and hardware.

The following are examples of tweets from Week 1 of MobiMOOC. The format for these examples is as follows: TWEET-TYPE: tweet. URLs and@usernames have been anonymized. It should be noted that while on Twitter it may seem as though a tweet is one type of post, the URL may prove that it is another completely different type of post. For instance, example 12 below may be a type of "link bait" that gets the reader to click on the link to read something relating to the course, but they end up at someone's website or blog that doesn't have a clear connection to the course in question.

1. EXCITEMENT: Week 1 of \#mobiMOOC is ending - we're still at the intro stage, there is still time to participate :-)
2. HELP: Participating in \#MobiMOOC from today, interested in: how to navigate through a massive amt of info and discussion; tips for \#mlearning.

3. HELP: anyone else using Google Voice in/outside the classroom? \#mobiMOOC

4. COMMENTARY ON PARTICIPATION: So apparently GMT +1 is different from BST (which I thought was GMT+1?) Sorry folks - \#mobiMOOC Elluminate finished. :-(

5. PARTICIPATION \& REFLECTION: \#mobiMOOC first post. New MOOC about Mobile Learning! URL-ANONYMIZED

6. PUBLICIZING: Read The \#mobiMOOC Daily • today's top stories via@username@username and @username URL-ANONYMIZED

7. RESOURCE: Two great mLearning presentations URL-ANONYMIZED \#slide2learn \#mobiMOOC ...and goodnight!

8. RESOURCE: Nice! --> Apple vs. All the Rest, a chart comparing \#Mobile App Stores from @username: URL-ANONYMIZED RT@username: \#mobiMOOC

9. RESOURCE: URL-ANONYMIZED mobile in the school? NO way, US report says \#mobiMOOC

10. RESOURCE: Missed \#MobiMOOC? - here's another opportunity $U R L-A N O N Y M I Z E D$ to advance your mobile skills

11. REFLECTION: Check out my PLE on the \#mobiMOOC course $U R L-A N O N Y M I Z E D$

12. OFF-TOPIC: Great, the first blog by a \#mobiMOOC is in! URL-ANONYMIZED Defecting to My Ears by Neil \#mobile

13. OFF-TOPIC: Video: Pet Shop Boys - Integral (JCRZ - QR Code Video Remix) URLANONYMIZED \#mobiMOOC

During Week 1 retweets were mostly retweets of resources posted on Twitter by other users, while reply tweets tended to be mostly informal conversations, including ice-breakers as learners were building their learning networks. The following are samples of reply tweets from Week 1:

A. CONVERSATION: @username \#mobiMOOC greetz from the Netherlands

B. CONVERSATION: @username Hello there $N A M E$ ! Are you with Kennisnet? URLANONYMIZED Good org! \#mobiMOOC

C. CONVERSATION \& COMMENTARY ON PARTICIPATION:@username@username yep thats me if i survive the \#mobiMOOC phenomena :)

\section{2) Week 2}

Most of the tweets for Week 2 are resources shared by MobiMOOC participants. There is a secondary cluster of tweets that could be considered chat, such as \#lrnchat chats that take place on Twitter. This chatter coincided with the live session of MobiMOOC for Week 2. These live chat tweets were a combination of asking for help (users could not see the chat in the live session so they took to Twitter to try and solve their issues); a commen- 
tary on participation; and reporting of user participation in the MOOC live session.

Other smaller pockets of tweet types, which were small but noticeable, are commentary on participation, and reflections on learning. We also see that there is still some demonstrable excitement about the MOOC posted to Twitter, perhaps both as a way to express oneself as well as a way to get more people to participate in the course. The interesting thing to note is that once issues with the live session chat were resolved, you don't see much chatter or discussion about the live session, which seems to indicate that, at least for this week, Twitter was used mostly as a support channel rather than a discussion channel for the live session. Examples of this are posts 3 through 8 below.

The following are example tweets from Week 2:

1. RESOURCE: More on NZ- Theory-Based Video Messaging Mobile Phone Intervention URLANONYMIZED \#hcsmanz \#mobiMOOC

2. RESOURCE: 5 Free iPhone Apps for the Classroom - URL-ANONYMIZED \#mobiMOOC

3. CHAT \& HELP: webinar \#mobiMOOC without chat?

4. CHAT \& HELP: \#mobiMOOC i can hear speaker but there is no chat?

5. CHAT \& HELP: webinar ended \#mobiMOOC ? did not start yet!

6. CHAT \& HELP: \#mobiMOOC audio is working fine read the chat please

7. CHAT \& HELP: Can anyone seethe chat in the Webinar? \#mobiMOOC

8. CHAT \& HELP: Listening to Judy Brown webinar \#MobiMOOC

9. COMMENTARY ON PARTICIPATION: Now with Judy Brown in \#mobiMOOC

10. CHAT \& HELP: chat for \#mobiMOOC on Twitter?

11. REFLECTION: Thinking a bit for \#MobiMOOC on stakeholders, audience, and localizing \#mlearning projects. URL-ANONYMIZED A blog post for Week 2.

12. EXCITEMENT: \#mobiMOOC is cool

Retweets during Week 2 focus for the most part, again, on retweeting resources. Humor seems to not escape MobiMOOC participants as we see them retweet a tongue-incheek tweet from another participant:

I. RT@MarkPower: Dear educators getting all moist about QR codes. They're just URL shorteners. Think about the content issues behind them please \#mobiMOOC

Reply tweets during Week 2 are clustered around two main categories: casual conversation, and asking for help, or rendering assistance to, fellow participants with the live session chat issues. This is the same as we saw during Week 1. As we see with example B the MobiMOOC participant seems to be chatting with someone external to the MOOC and MobiMOOC comes up peripherally in their conversation. This is the same as only seeing one side, or hearing only part of the conversation, since we are only getting a snapshot of what was said and not everyone is using the \#mobiMOOC tag.
A. CHAT \& HELP: @username Am I the only one who can see the chat?? \#MobiMOOC

B. CONVERSATION: @username I use my mobile device(s) much more than her!! She is ultra busy though..I do a lot with mobile and mlearning..you know \#mobiMOOC?

\section{3) Week 3}

The vast majority of original tweets were resources shared. This makes us wonder if a service like delicious or diigo, which provide social bookmark sharing, might be better for this type of sharing. Despite having the majority of tweets be about news and resource sharing, there were a few reflections on learning, and commentary on participation tweets. Examples of tweets from Week 3 are below. It's interesting to note that there are posts that may seem like self-promotion posts, similar to what we saw in Week 1 , but it is important to note that posts like example 1 are automatically generated by services like Paper.li, so the Twitter user may not have granular control of what is created and posted onto Twitter by this service.

1. OFF-TOPIC/SELF-PROMOTION: Read my latest@username newsletter: URL-ANONYMIZED New Word Structure App \#iear \#mlearning \#slide2learn \#edapp \#edtech \#mobiMOOC

2. PROMOTION BY ORGANIZER: Join the open $\&$ free course on mobile learning: \#MobiMOOC http://ignatiawebs.blogspot.com/2011/03/join-openand-free-course-on-mobile.html

3. RESOURCE: SlideShare presentation of Moura: \#Mobile Learning: SMS in educational contexts URL-ANONYMIZED \#mobiMOOC

4. COMMENTARY: "Getting close to the end of the semester, which means getting back to the interesting reading and \#mobiMOOC."

5. COMMENTARY: just signed-up for @,mobiMOOC - better late than never! http://mobiMOOC.wikispaces.com \#mobiMOOC \#mlearning

During Week 3, as well as preceding weeks, it was hard sometimes to determine whether something is was a retweet or a reply. There was one tweet (Example A below) that had the format of a Follow Friday tweet but had no follow friday hashtag (\#ff). Follow Friday tweets are recommendations of Twitter users to follow who are knowledgeable on a certain topic, or interesting people. Most of the reply tweets this week were casual conversations sharing resources and demonstrating excitement about something in the MOOC

A. FOLLOW FRIDAY?: @username@username @username@username@username@username \#mLearning

B. EXCITEMENT: @username you beat me - brilliant visualisation. \#mobiMOOC URLANONYMIZED

Another trend that continued this week was that tweets with resources were the type of tweets that were retweeted the most throughout the week. One noteworthy example is the tweet below which received quite a few retweets. In this retweet we see several things, and it is an example of how information on Twitter, especially during a MOOC, can be polymorphic. First, it is a resource that is shared 
with participants of not one, but three MOOCs. In addition to MobiMOOC this was shared with participants for Connectivism and Connected Knowledge (cck11) which ran concurrently with MobiMOOC; and it was shared with former participants of Personal Learning Environments and Knowledge Networks (PLENK2010), a MOOC that ran the year previous to MobiMOOC. This seems to indicate that there is at least an expectation that these hashtags for MOOCs are active long after the MOOC is completed.

In addition to the resource that it is, this is also an invitation to MOOC learners to participate in a debate and engage in a meta-learning discussion where the form of learning is debated, rather than the content. It is quite interesting to see that this type question, whether the MOOC is the death of traditional learning as we know it, still seems to be an area of debate today.

I. RT@username: MOOCs, the death of universities? Join the debate URL-ANONYMIZED \#mobiMOOC \#cck11 \#PLENK2010:... URLANONYMIZED

\section{4) Week 4}

The vast majority of original tweets for Week 4 were resource or news tweets shared by MobiMOOC participants. The other represented category was learner reflections which had a small handful of posts. What's interesting to note, both this week and in previous weeks, there had been tweets, by participants, in languages other than English, even though English was the predominant language for this MOOC. This is something we have seen anecdotally in other cMOOCs as well, where content of a personal tweet or blog post are reflections on learning in the native language of the speaker, but through the MOOC feed forward process, this is shared with all of the MOOC participants. One such example is example 2 below.

Examples of Week 4, original tweets:

1. RESOURCE: EDUCAUSE Mobile Computing Sprint // m-learning day URL-ANONYMIZED \#mobiMOOC \#EDUSprint

2. RESOUCE: 50 formas inovadoras de usar iPad en la Escuela URL-ANONYMIZED \#ecdigital \#mobiMOOC \#mlearning via@username

3. RESOURCE: firstName on \#mobiMOOC pointed to using goo.gl to create QR codes - cool! http://goo.gl/glnd

During Week 4 there were not many reply tweets, as a matter of fact we only had three reply tweets and they were all in the category of casual conversations. Retweets, this week, were all resources. The interesting thing is that some of them were also retweets of other participant's learner reflections. So, one participant's learner reflection becomes another learner's resource! Another interesting thing to note is that if we look at the quantitative analysis of Week 4 we can see that this is the point of lowest participation in the MOOC, at least from a Twitter posting perspective. It's interesting to see that the lowest level of participation on Twitter during this MOOC was mostly resource sharing.

\section{5) Week 5}

In Week 5 we see something interesting. In the original tweets we see reactions to what is happening in the live MobiMOOC session. In weeks past we had seen tweets relating to the live session, but they were mostly calls for help in order to troubleshoot issues with the live session.
This week we see reactions are that also, in a sense, reflections of learning and reactions to what is happening in the live session, not just reporting on what is being presented by the subject expert. This is something we have not seen since Week 2, which makes us wonder if participants only used Twitter as the backchannel for the live session only when the main presentation instrument did not have an adequate chat function for the participants.

Another potential explanation is that the preceding week David Metcalf presented and thus many more people viewed and reacted to the recording live session on Twitter this week. This is one of the reasons why learning analytics is important, and having a holistic picture of all the tools and participation modes is an important factor to keep in mind. MobiMOOC for instance utilized Twitter, live sessions, discussion boards, blogs, delicious, and other tools [12]. Examples of original tweets from Week 5 are as follows:

1. RESOURCE: Lots of wisdom for \#mhealth Bryan Alexander on Mobile Devices in Higher \#Education URL-ANONYMIZED \#hcsm \#hcsmanz \#mobiMOOC

2. RESOURCE: Sean Abajian - Technology \&amp;amp; Distance Learning Symposium http://t.co/2UKvEqV via @youtube \#mobiMOOC

3. CHAT/REFLECTION: "\#mobiMOOC in the nature of the jobs we do we are somehow in a protected area of education $=$ we are knowledge workers, large amount autonomy"

4. CHAT/REFLECTION: work in any place $=>$ mobile technologies can be monitored and can lead to surveillance and deskilling because connected to base \#mobiMOOC

5. CHAT/REFLECTION: distopic take on mobile technologies, does this have implications for education/training? \#mobiMOOC

Retweets this week are mostly resources, shared from the live session. Reply tweets were few and far between this week. No information could be really be discerned from the reply tweets there were available. The only tweet that was easily connected to something in the MOOC was a thank you note from a participant to the live session presenter:

A. @dmetcalf Thanks for your excellent \#mobiMOOC presentation. Very thought provoking and great examples as well.

\section{6) Week 6}

In the last week of MobiMOOC, Week 6, the majority of tweets fell into two categories: mobiMOOC chatter that revolved around the synchronous mobiMOOC session, and a sharing of resources. The interesting thing is that there were tweets with resources shared, but the tweets were just a short URL and the mobiMOOC hashtag. This makes us wonder whether the original poster of these tweets expected that people would click on these links based on the recognition of their name, even without some sort of description of what the link is all about; or whether this was some sort of "link bait" as we saw in Week 1. Examples of tweets from this week include the recording of this week's session, with course co-facilitator Andy Black (example 1). 
1. RESOURCE: AndyBlack 2011 \#k12 \#mLearning Part4 (of 5) http://t.co/gUS2kYm via@youtube \#mobiMOOC

2. RESOURCE: Participant-Name Presentation on MobiMOOC and survey results URLANONYMIZED \#mobiMOOC \#openeducation \#mobile mlearning \#FB

3. RESOURCE: 10 Open Education Resources You May Not Know About (But Should) URLANONYMIZED \#oer \#mobiMOOC

Reply tweets this week were mostly casual conversation and "thank you" to fellow participants, and to Andy Black, the presenter of the week's live session. As far as retweets go, again, the most popular type of retweet was one with shared resources! An interesting thing to note is exemplified by the tweet below (example A). This is a retweet in which a fellow participant retweets a call for help by a fellow Twitter use. The MobiMOOC participant probably did not know the answer to the question, but someone in MobiMOOC may have know, so the participant retweeted it to the group at large in order to put a spotlight on the issue.

A. HELP: RT@username: NZ teachers - where can we get docks for multiple I pod touch \#ipod.

\section{LIMITATIONS}

Like most studies that depend on Twitter data, this study has some limitations inherent with the data source. The first major limitation deals with URL shorteners such as bit.ly. The full URL data isn't always maintained long term by such services, so visiting these short URLs a year or more after they were posted means that sometimes you may come across dead URLs, a phenomenon sometimes referred to as "link rot." Sometimes, even if the full URL is available, the resource pointed to may no longer be available on that site. In these instances, unless that particular page was archived by archive.org, one has to use the text of the tweet to guess what type of resource the user was trying to share with others. Another issue relating to URLs is that their collection and categorization is a time consuming process. Since URLs don't come with associated content metadata it's up to the research team to visit every single URL and determine what type of resource is shared (text, video, audio, map, and so on) and what is the content and context of that shared resource.

The second big limitation is that there still aren't great tools that enable researchers to collect and analyze Twitter data easily. Crowdmap, which is powered by Ushahidi, does provide a way to collect tweets that contain a hashtag. However with the limitations imposed by the Twitter API (application programming interface) as to how often clients can call upon the service to get data from Twitter, researchers cannot know how much data there exists with a specific hashtag that wasn't collected. There are ways to have access to more complete data, such as having access to Twitter's "Firehose." This however is very costly and Twitter does not give this type of access to just anyone. The best alternative is a service like Crowdmap that has a cron job set to collect tweets throughout the day.

From an identity perspective it's not always easy to correlate who is posting what sort of information. It would have been very interesting if we were able to compare who was posting on Twitter with who was posting in the discussion forums. This way we could see how many of the MOOC participants were posting only in the discussion forums, how many only Twitter, and how many people in both. In future research it may be helpful for learners to have profiles, where their forum and Twitter identity are matched. This would have allowed us to make such medium posting comparisons.

The third issue revolves around using LIWC to gain some insight into the tweets collected. If all tweets were well-formed sentences using standard spelling, LIWC may very well work as well with tweets as it does with fuller bodies of text. However, since Twitter users compress what they write by using a variety of non-standard spelling mechanisms, including "text-speak," to fit their thoughts into the 140 character limit, LIWC, in its current incarnation, may not be an appropriate enough tool for Twitter data.

Finally, as Boyd et al [32] point out, there is no one way of retweeting. Boyd et al, in their article, show a variety of ways including, but not limited to: 'RT: @,', 'retweeting @', 'retweet @,', 'RT (via@)', 'HT@', 'MT @, , and 'r@.' While we didn't find as much variety in MobiMOOC's retweets it was indeed hard at times to determine if something was a retweet, or a reply. For instance consider the following tweet:

For Sure! RT@username is the earth round?

This tweet is a reply (or it is intended as one), but it has an embedded retweet as part of its structure. Does this tweet then count as a retweet, a reply, or both? To further complicate things, if the person writing the response ("For Sure!") doesn't necessarily intend to have the original poster, to whose question he is responding ("is the earth round?"), does this then make this tweet an original post? Without knowing the intent, it may be hard to accurately categorize tweets. Thus some underlying assumptions and rules need to be developed as tweets are analyzed and categorized.

\section{CONCLUSIONS \& FURTHER RESEARCH}

At the conclusion of our exploratory research we can say that we've shed some light on the tweeting behaviors of participants of MobiMOOC. First we see that tweeting participants, if they are left without prompts and modeling from course facilitators, contribute tweets that fall into three broad categories: (1) Tweets that were mostly about sharing links with news and resources to fellow participants in the course; (2) tweets that contained commentary about participation or that were reflections on the learning that occurred in the course; and (3) tweets that are related to live sessions of the course, but aren't necessarily a learning backchannel; this also includes getting help when technology fails the learner. The first two types seem to confirm previous research $[20,56]$. It's also interesting to note that at the lowest point of MOOC participation, the MOOC tweets were about sharing of resources, so one may see this as a baseline for tweeting behaviors during a MOOC.

The second thing we found is that, just like in other areas of the course, such as discussions [14], the height of content production from participants is during the first few weeks of the course. This might be seen as a sort of honeymoon period for participants, or something like a window-shopping period. Context-wise, while there seem to be some discussions in the Twitter stream, overall there 
isn't a lot of, what one could qualify as, discussion occurring in the Twitter stream. The tweets mostly resemble broadcasts from the tweeting participants. This seems to coincide with the findings of Ross et al [59] when they researched Twitter usage as a conference backchannel, and they described Twitter usage as a monologue. The weekly facilitators did not seem to have a strong presence on Twitter each week. Perhaps if MOOC facilitators model behavior on twitter, and through this modeling bring tweeting to the forefront of the course as another official medium of communication in the course, it might be possible that Twitter changes from a monologue to more of a dialogue in the course.

From a positive/negative sentiment analysis of the tweets, we saw that the overall the negative sentiment was very low; and we also saw that positive emotions hit their apex on Week 5 reply-tweets. We are wondering if at this point those replying to one another were members of the same learning community, and thus have developed a rapport which might explain this finding.

As other research has found [54], here too, Twitter usage as a means of communication in a course presents limited use, or utility, to a broader public. Resource links may be of interest to individuals outside of the MOOC, however reflections on learning and the live session backchannel doesn't provide much help to readers of tweets when they are not in that course mindset. This conjures up a feeling of "you had to be there" in order to get it. We also see that small minority of users produce a disproportionate amount of the tweets. This is something also discovered in other research such as Ross et al [59] and findings from Hawksey $[65,66]$ who looked at tweets from a more recent MOOC called Current and Future of Higher Education (CFHE12).

As far as twitter findings go that can assist learners and facilitators in Massive Open Online Classrooms succeed, these three baseline behaviors don't tell us a lot about what learning is happening in the classroom, other than twitter being another medium for troubleshooting or broadcasting your activities. For future research it would be interesting to see the interplay between discussion forums and twitter when course facilitators actively take to twitter to showcase lively discussions and important topics that go un-noticed. Since we did also observe that twitter was used as a troubleshooting medium for live sessions, it would be interesting to see how twitter usage varies when it's fostered as a live session backchannel, and how this is the same, or different, from other backchannel uses such as those in large classrooms $[48,53]$ and conferences [54$56,59]$.

As far as future directions for research go, there are many questions still looming regarding participation of learners in Twitter during the course. For instance, if we think about MOOCs as a large community of practice [67] it would be interesting to examine the role of core versus peripheral members in a MOOC, their participation and contributions to the course, as well as the type, and frequency, of content contributed.

It would be interesting to study the effects of different marketing strategies for MOOCs during their initial week on microblogging social media such as Twitter and google+; and to then observe any potential increase of original tweets or retweets due to this marketing period. It appears that during the first week many learners are win- dow shopping in the MOOC to see if the course would work for them; and after a week or so, a decision has been made by the learner as to whether to stick with the course or not. This is akin to dropping a course during a university's add/drop period. Along these lines, it would be interesting to see the effects of a "warm-up week," before the first week of a course, and a plenary week, after the last week of the course, on the original tweets, retweets and sharing throughout the MOOC, and as stated above, more facilitator involvement in the medium.

It would also be interesting to compare and contrast, more in-depth, tweets that do not contain links with discussion forums in the course. While we did find that Twitter contributions seem a lot like monologues, we wonder what the differences may be if tweet-chats were institutionalized as part of the course. A discussion context analysis between these two forms may yield interesting insights. This is also where one could examine in more detail the positive retweets to negative retweets trends. Are there really parts of the course where they become the inverse of one another? If so, why does this happen? Finally, since we can't claim to be able to describe tweeting behaviors in all MOOCs from an analysis of tweeting behaviors in one MOOC, a cMOOC to be more specific, it would be worthwhile to examine tweeting behaviors longitudinally across MOOCs, both cMOOCs and xMOOCs.

\section{REFERENCES}

[1] A. Azevado, "In Colleges' Rush to Try MOOC's, Faculty Are Not Always in the Conversation," 2012. [Online]. Available: http://chronicle.com/article/In-Colleges-Rush-to-Try/134692/. [Accessed 20 April 2013].

[2] M. Bousquet, "Good MOOC's, Bad MOOC's," 2012. [Online]. Available: Available: http://chronicle.com/blogs/brainstorm/goodmoocs-bad-moocs/50361. [Accessed 20 April 2013].

[3] S. Kolowich, "MOOCs for Credit," 2012. [Online]. Available: http://www.insidehighered.com/news/2012/10/29/coursera-strikesmooc-licensing-deal-antioch-university. [Accessed 20 April 2013].

[4] J. Lane and K. Kinser, "MOOC's and the McDonalizations of Global Higher Education," 2012. [Online]. Available: http://chronicle.com/blogs/worldwise/moocs-mass-education-andthe-mcdonaldization-of-higher-education/30536. [Accessed 20 April 2013].

[5] J. R. Young, "American Council on Education May Recommend Some Coursera Offerings for College Credit," 2012. [Online]. Available: http://chronicle.com/article/MOOCs-Take-a-MajorStep/135750/. [Accessed 20 April 2013].

[6] S. Vaidhyanathan, "What's the matter with MOOCs?," 2012. [Online]. Available: http://chronicle.com/blogs/innovations/whatsthe-matter-with-moocs/33289. [Accessed 20 April 2013].

[7] L. Pappano, "The Year of the MOOC," 2 November 2012. [Online]. Available: http://www.nytimes.com/2012/11/04/edu cation/edlife/massive-open-online-courses-are-multiplying-at-arapid-pace.html?pagewanted $=$ all\&_r $=0$. [Accessed 18 December 2012].

[8] G. Siemens, "MOOCs are really a platform," 15 July 2012. [Online]. Available: http://www.elearnspace.org/blog/2012/07/25/ moocs-are-really-a-platform/. [Accessed 18 December 2012].

[9] S. Downes, "What is a MOOC?," 9 April 2013. [Online]. Available: http://www.youtube.com/watch?v=eW3gMGqcZQc. [Accessed 20 April 2013].

[10] D. Cormier, "What is a MOOC?" 2011. [Online]. Available: http://www.youtube.com/watch?v=eW3gMGqcZQc. [Accessed 20 April 2012].

[11] R. Kop, H. Fournier and J. Mak, "A pedagogy of abundance or a 


\section{SPECIAL FOCUS PAPER \\ What TweEts TELl us ABOUT MOOC PARTICIPATION}

pedagogy to support human beings? Participant support on massive open online courses," The International Review Of Research In Open And Distance Learning, vol. 12, no. 7, pp. 74-93, $2011 \mathrm{a}$.

[12] I. deWaard, A. Koutropoulos, N. Keskin, M. Gallagher, S. Abajian, R. Hogue and C. Rodriguez, "Exploring the MOOC format as a pedagogical approach for mLearning," in mLearn 2011: 10th World Conference on Mobile and Contextual Learning, Beijing, $2011 \mathrm{a}$.

[13] I. deWaard, S. Abajian, M. Gallagher, R. Hogue, N. Keskin, A. Koutropoulos and O. Rodriguez, "Using mLearning and MOOCs to understand chaos, emergence, and complexity in education," International Review of Research in Open and Distance Learning, vol. 12, no. 7, pp. 94-115, 2011 b.

[14] A. Koutropoulos, M. Gallagher, S. Abajian, I. deWaard, R. Hogue, N. Keskin and O. Rodriguez, "Emotive Vocabulary in MOOCs: Context \& Participant Retention," EuroDL: The European Journal of Open, Distance and E-Learning, vol. 2012, no. I, 2012.

[15] C. O. Rodriguez, "MOOCs and the AI-Stanford like Courses: Two Successful and Distinct Course Formats for Massive Open Online Courses," EuroDL, vol. 2012, no. II, 2012.

[16] C. Rodriguez, "Two Distinct Course Formats In The Delivery of Connectivist MOOCs," Turkish Online Journal of Distance Education-TOJDE, vol. 14, no. 2, Article 3, 2013.

[17] R. Kop and H. Fournier, "New Dimensions to Self-directed Learning in an Open Networked Learning Environment," International Journal of Self-Directed Learning, vol. 7, no. 2, pp. 1-18, 2011.

[18] R. Kop and F. Carroll, "Cloud Computing and Creativity: Learning on a Massive Open Online Course," European Journal of Open, Distance and E-Learning, no. Special Issue on Creativity and OER, 2011.

[19] A. Ravenscroft, "Dialogue and Connectivism: A new approach to understanding and promoting dialogue-rich Networked Learning," International Review of Research in Online and Distance Learning, vol. 12, no. 3, 2011 .

[20] F. Gao, T. Luo and G. Zhang, "Tweeting for learning: A critical analysis of research on microblogging in education published in 2008-2011," British Journal of Education Technology, vol. 43, no. 5, pp. 783-801, 2012. http://dx.doi.org/10.1111/j.1467-8535.2012. 01357.x

[21] M. Arrington, "Odeo Releases Twttr," 15 July 2006. [Online]. Available: http://techcrunch.com/2006/07/15/is-twttr-interesting/. [Accessed 26 December 2012].

[22] L. Dugan, "Twitter to Surpass 500 Million Registered Users on Wednesday," 21 February 2012. [Online]. Available: http://www.mediabistro.com/allTwitter/500-million-registeredusers b18842. [Accessed 16 December 2012].

[23] A. Java, X. Song, T. Finin and B. Tseng, "Why We Twitter: Understanding Microblogging Usage and Communities," in Proceedings of the 9th WebKDD and 1st SNA-KDD 2007 workshop on Web mining and social network analysis, San Jose, CA, 2007. http://dx.doi.org/10.1145/1348549.1348556

[24] M. Cheong, "'What are you Tweeting about?': A survey of Trending Topics within Twitter," Clayton School of Information Technology, Monash University, vol. Technical Report 2009, no. 251, 2009.

Available:http://citeseerx.ist.psu.edu/viewdoc/download?doi=10.1.1.158. 4679\&rep=rep1\&type=pdf [Accessed 5 August 2012]

[25] M. Cheong and V. Lee, "Integrating Web-based Intelligence Retrieval and Decision-making from the Twitter Trends Knowledge Base," in SWSM'09, Hong Kong, 2009.

[26] W. Weerkamp, S. Carter and M. Tsagkias, "How People use Twitter in Different Languages," 2001. [Online]. Available: http://journal.webscience.org/539/. [Accessed 5 August 2012].

[27] D. Laniardo and P. Mika, "Making sense of Twitter," International Semantic Web Conference, Part I, vol. 6496, pp. 470-485, 2010.

[28] B. A. Huberman, D. M. Romero and F. Wu, "Social networks that matter: Twitter under the microscope," 2009. [Online]. Available: http://firstmonday.org/htbin/cgiwrap/bin/ojs/index.php/fm/article/ view/2317. [Accessed 5 August 2012].

[29] L. Hong, G. Convertino and E. H. Chi, "Language Matters in Twitter: A Large Scale Study," in Proceedings of the Fifth International AAAI Conference on Weblogs and Social Media, Barcelona, 2011.

[30] C. Honeycut and S. C. Herring, "Beyond Microblogging: Conversation and Collaboration via Twitter," in Proceedings of the 42nd Hawai'i International Conference on System Sciences (HICSS42), Los Alamitos, 2009. Available: http://www.ledbetter.de/pdf/beyondmicroblogging.PDF [Accessed 5 August 2012]

[31] B. Poblete, R. Garcia, M. Mendoza and A. Jaimes, "Do All Birds Tweet the Same? Characterizing Twitter Around the World.," 2011. [Online]. Available: http://dl.acm.org/citation.cfm?doid=2063576.2063724.

[32] D. Boyd, S. Golder and G. Lotan, "Tweet, Tweet, Retweet: Conversational Aspects of Retweeting on Twitter," in Proceedings of HICSS-43., Kauai, 2010.

[33] B. Krishnamurthy, P. Gill and M. Arlitt, "A few chirps about Twitter," in Proceedings of the 1st workshop on Online social networks, Seattle, 2008. http://dx.doi.org/10.1145/1397735. 1397741

[34] D. Westerman, P. R. Spence and B. Van Der Heide, "A social network as information: The effect of system generated reports of connectedness on credibility on Twitter," Computers in Human Behavior, vol. 28, pp. 199-206, 2011. http://dx.doi.org/10.1016/ j.chb.2011.09.001

[35] E. Fischer and A. R. Reuber, "Social interaction via new social media: (How) can interactions on Twitter affect effectual thinking and behavior?," Journal of Business Venturing, vol. 26, pp. 1-18, 2010. http://dx.doi.org/10.1016/j.jbusvent.2010.09.002

[36] S. Carter, M. Tsagkias and W. Weerkamp, "Twitter hashtags: Joint Translation and Clustering," 2011. [Online]. Available: http://journal.webscience.org/529/. [Accessed 5 August 2012].

[37] H.-C. Chang, "A New Perspective on Twitter Hashtag Use: Diffusion of Innovation Theory," 2010. [Online]. Available: http://mail.asis.org/asist2010/proceedings/proceedings/ASIST A M10/submissions/295 Final Submission.pdf. [Accessed 5 August 2012]

[38] J. Huang, K. M. Thornton and E. N. Efthimiadis, "Conversational Tagging in Twitter," in Proceedings of HT'10, Toronto, 2010.

[39] B. Suh, L. Hong, P. Pirolli and E. H. Chi, "Want to be retweeted? Large scale analytics on factors impacting retweet in Twitter network," in IEEE Second International Conference on Social COmputing, 2010.

[40] S. A. Macskassay \& M. Michelson, "Why Do People Retweet? Anti-Homophily Wins the Day!," in Proceedings of the Fifth International AAAI Conference on Weblogs and Social Media, 2011.

[41] S. Petrovic, M. Osborne and V. Lavrenko, "RT to Win! Predicting Message Propagation in Twitter," in Proceedings of the Fifth International AAAI Conference on Weblogs and Social Media, Barcelona, 2011.

[42] A. Gruzd, S. Doiron and P. Mai, " Is Happiness Contagious Online? A Case of Twitter and the 2010 Winter Olympics," in Proceedings of the 44th Hawaii International Conference on System Sciences (HICSS), Kauai, 2011.

[43] C. J. Case and D. L. King, "Cutting Edge Communication: Microblogging At The Fortune 200, Twitter Implementation and Usage," Issues in Information Systems, vol. XI, no. 1, pp. 216-223, 2010 .

[44] R. D. Waters and J. Y. Jamal, "Tweet, tweet, tweet: A content analysis of nonprofit organizations' Twitter updates," Public Relations Review, vol. 37, pp. 321-324, 2011. http://dx.doi.org/10.1016/j.pubrev.2011.03.002

[45] R. D. Waters \&. J. M. Williams, "Squawking, tweeting, cooing, and hooting: analyzing the communication patterns of government 
agencies on Twitter," J. Publ. Aff., vol. 11, pp. 353-363, 2011. doi: 10.1002/pa.385http://dx.doi.org/10.1002/pa.385

[46] G. Veletsianos, "Higher education scholars' participation and practices on Twitter," Journal of Computer Assisted Learning, vol. 28, pp. 336-349, 2012. http://dx.doi.org/10.1111/j.13652729.2011.00449.x

[47] K. Manzo, "Twitter Lessons in 140 Characters or Less. (Cover story)," Education Week, Proceedings of CIKM'11, vol. 29, no. 8, pp. 1-14, 2009.

[48] K. Smith, "The Twitter Experiment [video]," 2009. [Online]. Available: http://www.youtube.com/watch?v=6WPVWDkF7U8. [Accessed 31 December 2012].

[49] R. Junco, G. Heiberg and E. Loken, "The effect of Twitter on college student engagement and grades," Journal of Computer Assisted Learning, vol. 27, pp. 119-132, 2011. http://dx.doi.org/10.1111/j.1365-2729.2010.00387.x

[50] K. Stepanyan, K. Borau and C. Ullrich, "A social network analysis perspective on student interaction within the Twitter microblogging environment," in 10th IEEE International Conference on Advanced Learning Technologies, Sousse, 2010.

[51] S. Jaworowski, "Twitter in Action: One Professor's Experience," Proceedings of TCC 2010, vol. 2010, pp. 110-117, 2010.

[52] K. Borau, C. Ulrich, J. Feng and R. Shen, "Microblogging for Language Learning: Using Twitter to Train Communicative and Cultural Competence," Proceedings of ICWL 2009, LNCS 5686, pp. 78-87, 2009. Available: http://www.carstenullrich.net/pubs/ Borau09Microblogging.pdf [Accessed 5 August 2012]

[53] C. M. Elavsky, C. Mislan and S. Elavsky, "When talking less is more: exploring outcomes of Twitter usage in the large-lecture hall," Learning, Media and Technology, vol. 36, no. 3, pp. 215233, 2011. http://dx.doi.org/10.1080/17439884.2010.549828

[54] M. Ebner, H. Mühlburger, S. Schaffert, M. Schiefner and W. Reinhardt, "Get Granular on Twitter - Tweets from a Conference and their Limited Usefulness for Non-Participants," KCKS 2010, IFIP AICT 324, pp. 102-113, 2010.

[55] K. Weller, E. Dröge and C. Puschmann, "Citation Analysis in Twitter. Approaches for Defining and Measuring Information Flows within Tweets during Scientific Conferences," in Proceedings of Making Sense of Microposts Workshop, Co-located with Extended Semantic Web Conference, Crete, 2011.

[56] W. Reinhardt, M. Ebner, G. Beham and C. Costa, "How People are using Twitter during Conferences," Creativity and Innovation Competencies on the Web, pp. 145-156, 2009.

[57] M. Ebner, C. Lienhardt, M. Rohs and I. Meyer, "Microblogs in Higher Education - A chance to facilitate informal and processoriented learning?," Computers \& Education, vol. 55, no. 1, pp. 92-100, 2010. http://dx.doi.org/10.1016/j.compedu.2009.12.006

[58] E. Vega, R. Parthasarathy and J. Torres, " Where are my tweeps?: Twitter Usage at Conferences," 2010. [Online]. Available: http://www.socialcouch.com/demos/final paper_Twitter.pdf. [Accessed 5 August 2012].

[59] C. Ross, M. Terras, C. Warwick and A. Welsh, "Enabled Backchannel: Conference Twitter Use by Digital Humanists," Journal of Documentation, vol. 67, no. 2, pp. 214-237, 2011. http://dx.doi.org/10.1108/00220411111109449

[60] Crowdmap, "About Crowdmap," 2012. [Online]. Available: https://crowdmap.com/mhi/page/4. [Accessed 12 December 2012].

[61] V. Venkatesh and H. Bala, "Technology Acceptance Model 3 and a Research Agenda on Interventions," Decision Sciences, vol. 39, no. 2, pp. 273-315, 2008. http://dx.doi.org/10.1111/j.15405915.2008.00192.x

[62] T. O'Reilly and S. Milstein, The Twitter Book, Sebastopol: O’Reilly Media, Inc., 2009.

[63] M. Perreault and D. Ruths, "Why Do People Retweet? AntiHomophily Wins the Day!," in Proceedings of the Fifth International AAAI Conference on Weblogs and Social Media, Barcelona, 2011.
[64] J. Pennebaker, R. Booth and M. Francis, " Linguistic Inquiry and Word Count [Software]," 2007. [Online]. Available: http://www.liwc.net. [Accessed 20 October 2011].

[65] M. Hawksey, "CFHE12 Week 3 Analysis: Exploring the Twitter network through tweets," 28 October 2012. [Online]. Available: http://mashe.hawksey.info/2012/10/cfhe12-week-3-analysisexploring-the-Twitter-network-through-tweets/. [Accessed 12 December 2012].

[66] M. Hawksey, "CFHE12 Analysis: Summary of Twitter activity," 26 November 2012. [Online]. Available: $\mathrm{http}: / /$ mashe.hawksey.info/2012/11/cfhe12-analysis-summary-ofTwitter-activity/. [Accessed 12 December 2012].

[67] E. Wenger, "Communities of Practice: Learning as a social system," The Systems Thinker, vol. 9, no. 5, 2009.

\section{ADDITIONAL BIBLIOGRAPHY}

[68] B.P. Blake, N. Agarwal, R.T. Wigland and J.D. Wood, "Twitter quo vadis: Is Twitter bitter or are tweets sweet", in Proceedings of the Seventh International Conference on Information Technology, 2010, pp. 1257-1260.

[69] J. Bollen, A. Pepe and H. Mao, "Modeling public mood and emotion: Twitter sentiment and socioeconomic phenomen," in Proceedings of the Fifth International AAAI Conference on Weblogs and Social Media, 2011

[70] G.M. Chen, "Tweet this: A uses and gratifications perspective on how active Twitter use gratifies a need to connect with others," in Computers in Human Behavior, 2010, pp. 755-762.

[71] M.D. Choudhury, N. Diakopoulos and M. Naaman, "Unfolding the Event Landscape on Twitter: Classification and Exploration of User Categories" in Proceedings of CSCW 2012, 2012.

[72] A. Cornwall, "Unpacking 'participation': Models, meanings, and practices," in Community Development Journal, vol. 43, no. 3, pp. 269-283. http://dx.doi.org/10.1093/cdj/bsn010

[73] J. C. Dunlap and P.R. Lowenthal, "Tweeting the night away: Using Twitter to enhance social presence," in Journal of Information Systems Education, vol. 20, no. 2, 2009.

[74] H. Fournier and R. Kop, "Factors affecting the design and development of a Personal Learning Environment: Research on superusers," in International Journal of Virtual and Personal Learning Environments, vol. 2, no. 4, 2011. pp.12-22. http://dx.doi.org/10.4018/jvple.2011100102

[75] S. Goankar, J. Li, R.R. Choudhury, L. Cox and A. Schmidt, "Micro-Blog: Sharing and Querying Content Through Mobile Phones and Social Participation," in Proceedings of MobiSys'08, 2008.

[76] G. Grosseck and C. Holotescu, "Can we use Twitter for educational activities?" in Fourth International Scientific Conference eLearning and Software for Education, 2008

[77] B. J. Jansen, M. Zhang, K. Sobel and A. Chowdury, "Twitter power: Tweets as electronic word of mouth," Journal of the American Society for Information Science and Technology, vol. 60, 2009. pp. 1-20. http://dx.doi.org/10.1002/asi.21149

[78] P. Johnson and S. Yang, "Uses and gratifications of Twitter: An examination of user motives and satisfaction of Twitter us," in The Annual Meeting of the Association for Education in Journalism and Mass Communication, 2009

[79] E. Kiciman, "Language Differences and Metadata Features on Twitter," in Proceedings of SIGIR 2010 WEB N-GRAM Workshop, Geneva, Switzerland, 2010, pp. 47-51.

[80] J. Letierce, A. Passant, S. Decker and J. Breslin, "Understanding how Twitter is used to spread scientific messages," in Web Science Conference, 2010

[81] I.L.B. Liu, C.M.K. Cheung, and M.K.O. Lee, "Understanding Twitter Usage: What Drive People Continue to Tweet." in PACIS 2010 Proceedings, Paper 92, 2010. Available: http://aisel.aisnet.org/pacis2010/92.

[82] J. Mackness, S. Mak and R. Williams, "The ideals and reality of participating in a MOOC," in Proceedings of the 7th International Conference on Networked Learning, Lancaster, 2010, pp. 266275.

[83] R. Pfitzner, A. Garas and F. Schwitzer, "Emotional Divergence Influences Information Spreading on Twitter," in Proceedings of 
the Sixth International AAAI Conference on Weblogs and Social Media, 2012

[84] V. Pornsakulvanich, P. Haridakis and A.M. Rubin, "The influence of dispositions and Internet motivation on online communication satisfaction and relationship closeness," in Computers in Human Behavior. 24. pp. 2292-2310. http://dx.doi.org/10.1016/j.chb.2007. 11.003

[85] D. A. Shamma, L. Kennedy and E.F. Churchill, "Tweet the Debates: Understanding Community Annotation of Uncollected Sources," in Proceedings of WSM'09, 2009. pp. 3-10.

[86] D. A. Shamma, L. Kennedy and E.F. Churchill, "Tweetgeist: Can the Twitter Timeline Reveal the Structure of Broadcast Events?" in Proceedings of CSCW 2010. 2010. pp. 589-593.

[87] Tumasjan, A., Sprenger, T. O., Sandner, S.G. \& I.M Welpe "Predicting elections with Twitter: What 140 characters reveal about political sentiment." In International AAAI Conference on Weblogs and Social Media, Washington, D.C., 2010. pp. 178-185.

[88] C. Williams \& G. Gulati. "Social Networks in Political Campaigns: Facebook and Congressional Elections 2006, 2008." Unpublished. 2009

[89] F. Grau and J. Xifra. "Nanoblogging PR: The discourse on public relations in Twitter." Public Relations in Review. 36. 2010, pp. 171-174. http://dx.doi.org/10.1016/j.pubrev.2010.02.005

[90] D. Zhao and M. Rosson. "How and why people Twitter: the role that micro-blogging plays in informal communication at work." In Proceedings of GROUP '09, 2009, pp. 243-252. http://dx.doi.org/10.1145/1531674.1531710

\section{AUTHORS}

A. Koutropoulos is with the University of Massachusetts Boston, Boston, MA 02125 USA (e-mail: a.koutropoulos@umb.edu). He is the Program Coordinator for the Applied Linguistics Online MA program, as well as an adjunct faculty member with the department of Instructional Design at UMass Boston. He holds an MBA, an MS in Information Technology, an MA in Applied Linguistics, and MEd in Instructional Design and a BA in Computer Science.

S. C. Abajian is an award winning public school teacher in Los Angeles and a graduate student at California State University, Northridge completing his M.A. in Education Administration. Sean is also a political campaign consultant helping progressive teachers get elected to their local school boards using the latest in technology combined with traditional grassroots methods. Additionally, he is the co-owner of a successful small business which has provided a weekly organic produce service to $1000+$ families. Sean grew up in Central Africa and has lived in France, Belgium and Spain. He speaks French, Spanish, Catalan, Tshiluba and Lingala. Sean graduated from Occidental College and lives in South Pasadena with his wife, Dr. Suzie Abajian.

I. de Waard is a Doctorandus at the Open University of the United Kingdom. She has started and coordinated multiple mobile, MOOC and online projects. Inge has a background in IT and education, and has been involved in mobile and eLearning from 1999 onward. In 2011 and
2012 Inge de Waard organized MobiMOOC, a free Open Online Course on mLearning. She has been given a number of awards related to corporate and academic excellence in eLearning: 2010 Gold Medal Award for Excellence in Mobile Learning from Brandon Hall, 2012 Excellence in Research Award from Athabasca University, 2013 the Gold medal for Academic excellence provided by the Governor General of Canada. And above all she likes to connect with inspiring people, so feel free to connect.

R. J. Hogue is a $\mathrm{PhD}$ Candidate with the Faculty of Education at the University of Ottawa, Ottawa, Canada (email: rebecca.hogue@uottawa.ca). She is relocating to San Jose California. Her professional background is in instructional design and software quality assurance. She holds a Master of Arts Degree in Distributed Learning (Distance Education), and a Bachelor of Science Degree in Computer Science. Her passion is for creating innovative solutions to teaching and learning challenges. Her current research involves creating faculty development resources for integrating tablet technology into clinical medical education.

N. Ö. Keskin s with the Distance Education Department, Anadolu University, Eskisehir, Turkey. (e-mail: nilgunokeskin@gmail.com). She received her Ph.D. in Anadolu University Educational Sciences Institution, Department of Computer Education and Instructional Technologies in 2011. She served as visiting researcher at University of Central Florida (2009-2010), and as research assistant at Open Education Faculty, Anadolu University (2005-2012). She still continues to serve as assistant of professor at Anadolu University. She is currently working as an executive coordinator of Photography and Cameraman Associate Degree Program, an E-portfolio System Coordinator of Public Service Practice Course for Preschool Teacher Training Program, and an assistant of Erasmus Coordinator for Open Education Faculty. She has international and national articles on educational technology, mobile learning, massive open online course, and open and distance education. Her research interests include instructional design, online learning, mobile learning, open and distance education, multi-platform system design and e-portfolios.

C. O. Rodriguez is "Investigador Principal" from CONICET (Consejo Nacional de Investigaciones) Argentina. (email: cor_ar@yahoo.com). He holds a PhD in Physics and has been an Alexander von Humboldt Scholar in Germany for several years. He has more than 100 publications in the most credited international journals.. His research interests have moved to the study of the impact of ICT in undeserved communities and more recently Open Online Education and changes in Education.

Submitted, May, 11, 2013. Published as resubmitted by the authors on October, 31, 2013. 